[0212-7199 (2003) 20: 10; pp 501-503] ANALES DE MEDICINA INTERNA Copyright (C) 2003 ARAN EDICIONES, S.L.

AN. MED. INTERNA (Madrid) Vol. 20, N. ${ }^{\circ} 10$, pp. 501-503, 2003

\title{
Adicción a drogas: consumo y consecuencias en continuo cambio
}

Gutiérrez del Río C. Adicción a drogas: consumo y consecuencias en continuo cambio. An Med Interna (Madrid) 2003; 20 : $501-503$.

El consumo de drogas y la adicción que producen se ha llegado a considerar una enfermedad crónica; ha generado una amplia y variada literatura sobre el tema. Se conoce en nuestro país desde la década de los años 70 , coincidiendo con la llegada del Hachís (1,2). Posteriormente, hemos asistido a una progresiva evolución, con la aparición de distintos perfiles, tanto de consumo de sustancias, como de vía de administración utilizada o de patología asociada al mismo.

En los años 80 adquiere gran importancia el consumo de Heroína. Esta sustancia revoluciona, de alguna forma, el mundo de la drogadicción pues conlleva un incremento de los problemas delictivos y de salud; todo esto genera un aumento de la demanda de atención, así como de la morbi-mortalidad asociada $(3,4)$. Esta adicción se generaliza en una población con una edad media joven, entre los 20 y 30 años, según se recoge en la literatura; en el estudio de Cobos y cols., la edad es aún mayor, lo que podría deberse al momento en que se realiza el trabajo y, al hecho de que el $50 \%$ de los pacientes llevaban más de 10 años de adicción $(1,5,6)$.

Por otro lado, al menos inicialmente, la vía preferente de consumo fue la intravenosa (i.v.), lo que unido a la marginalidad que conllevaba la adicción a estas sustancias, con altas tasas de inestabilidad laboral, comisión de acciones delictivas, deficiente estado nutricional y pobre higiene, dio lugar a un elevado número de complicaciones infecciosas $(2,3,7)$. En este sentido, la aparición de infecciones se podría decir que sigue la ruta del tóxico, desde su llegada al organismo: infecciones de partes blandas (celulitis, abscesos, piomiositis...), infección por virus de hepatitis B, C, virus de inmunodeficiencia humana (VIH), etc. Esta última infección, como es bien conocido y, al menos hasta la llegada de la terapia denominada HAART, conllevaba una creciente inmunodepresión con la consiguiente aparición de infecciones oportunistas (candidiasis, toxoplasmosis, neumonía por Pneumocistis carinii, etc.). Además existen otras infecciones, también presentes en la población general, pero que aquí, quizás por las condiciones ya comentadas, son más prominentes: neumonías bacterianas, tuberculosis, etc. (1,3-5,8-10).

En cualquier caso, en este colectivo las infecciones, no llegarían sólo por vía i.v., si no que dada la marginalidad referi- da, se genera importante promiscuidad sexual, con lo que presentan, con frecuencia, enfermedades de transmisión sexual que, siempre, deberían ser un centinela sobre una posible de infección por VIH; de hecho, en la actualidad, se está observando que la categoría de transmisión más frecuente está dejando de ser el consumo de drogas por vía parenteral, para ser la vía sexual $(2,4,8,10-12)$.

Por todo lo referido, la mayoría de los pacientes que ingresan en un hospital general lo hacen en los servicios de Medicina Interna, seguido de los de Obstetricia, dado que las pacientes adictas se encuentran en una edad fértil; no obstante, conviene destacar que la población femenina adicta a drogas representa, en todas las series, alrededor de, sólo, un $20 \%(1,2,11)$.

Como cabía pensar, todas estas complicaciones se han asociado a estancias medias elevadas, fundamentalmente, en el caso de ingresos relacionados con la infección por VIH, así como a frecuentes reingresos.

No obstante, la adicción a drogas se ha ido modificando con el paso del tiempo y, en los años 90, asistimos al declive del uso de la vía i.v. a favor de otras, probablemente en relación con las numerosas campañas divulgativas sobre el riesgo del uso de dicha vía y el temor a la infección por VIH $(3,5,8,13)$. Por esto, llama la atención que, en el trabajo de Cobos y cols., la vía más utilizada por los pacientes, en el año 1999, (fecha en que se lleva a cabo el estudio), sea la i.v.; esto pudiera estar en relación con lo que, ya ellos mismos indican: se trata de un trabajo retrospectivo y no tienen posibilidad de recoger si seguía siendo utilizada dicha vía, lo que, por otro lado, explicaría el escaso número de infecciones de partes blandas recogidos (6); en este aspecto, destacar que este tipo de infecciones no siempre ingresan en los hospitales, sino que frecuentemente son atendidos en los centros de Atención Primaria o en los servicios de Urgencias.

Pero el abandono de la vía i.v. y el uso de otras, como la vía fumada, no supone que no existan complicaciones; así se ha observado, sobre todo desde la segunda mitad de los años 90, un incremento del asma, considerándose la insuflación de heroína un hecho fuertemente relacionado (14).

Además del cambio de vía de acceso, a favor del consumo de sustancias fumado, inhalado o por vía oral, se observó la 
irrupción de otras drogas como Cocaína, con sus correspondientes complicaciones orgánicas y, así, su uso puede implicar:

-Aumento de los cuidados de salud (ingresos, morbi mortalidad, estancias, etc.) e, incluso, también se pueden incrementar los costes en la atención de hijos de madres adictas en el embarazo (15).

-Desarrollo de insuficiencia renal crónica, en relación con mayor estrés, mayor abuso de sustancias, etc. (16).

-Tampoco podemos olvidar que su consumo se asocia, al igual que el de la Heroína, al desarrollo de infecciones; en cambio, los ingresos por causas gastrointestinales o traumáticas son menos frecuentes que con el consumo de otras sustancias como marihuana o alcohol (17).

-Desarrollo de patología cardiaca (taquicardias, procesos coronarios, etc.). En este aspecto, recientemente, Weber y cols., indican que los pacientes usuarios de Cocaína que acuden por dolor torácico y no presentan cambios isquémicos en el electrocardiograma o elevación de la troponina, durante un periodo de observación de 9 a 12 horas, tienen baja probabilidad de infarto agudo de miocardio o muerte en los 30 días posteriores al alta (18).

- Trastornos neuropsiquiátricos con alucinaciones, desarrollo de demencias, hemorragias, etc.

En los años 90, también, se apreció un aumento del consumo de anfetaminas, probablemente en relación con la crisis económica y la elevada tasa de desempleo (19).

Tampoco, se puede olvidar el resurgir del Cannabis, el mantenimiento de la adicción a Benzodiacepinas por vía oral $\mathrm{y}$, el creciente consumo, sobre todo en población muy joven, de alcohol; con estas dos últimas sustancias se observa mayor deterioro cognitivo y distres psicológico que con la dependencia a otras drogas (20).

$\mathrm{Y}$, en esta continua evolución en el mundo de la drogadicción aparecen las "drogas de diseño" o de "síntesis", es decir, sustancias sintetizadas en laboratorios clandestinos, que incluyen: derivados de las feniletilaminas (MDMA, MDA, MDEA y otras anfetaminas, speed, etc.), arilciclohexaminas (PCP y ketamina), opioides de síntesis ( $\alpha$-metilfentanilo, 3-metilfentanilo), derivados de la metacuolona o el oxibato sódico (21), (22).

Generalmente se consumen en discotecas de música "tecno" o en macrofiestas, en cantidades ingentes, acompañadas de otras múltiples drogas como alucinógenos, Cocaína, Flunitrazepam, etc. Dan lugar a frecuentes intoxicaciones, visitas a los servicios de Urgencias o síndrome de secreción inadecuada de ADH por reposición de líquidos inadecuada; por otro lado, estas drogas pueden derivar, a más largo plazo, en complicaciones neurológicas, al afectar al sistema dopaminérgico y serotoninérgico (22-24).

Existe, por tanto, un amplio arsenal de sustancias de consumo, partiendo de las consideradas legales hasta las de nueva aparición, con una cambiante ruta de administración y de características epidemiológicas; por ello, a pesar de la amplia literatura existente se requieren más estudios que permitan trazar un dibujo del consumidor, en cada momento, así como, de las potenciales complicaciones, con vistas a intentar una prevención eficaz. En este sentido, han contribuido mucho los Centros de Atención y Seguimiento de drogodependencias (CAS) que se han encargado de prescribir sustancias sustitutivas como Metadona, de preconizar los beneficios del cambio de la vía de administración de la droga, de luchar contra la extensión del VIH, de extender programas de vacunaciones o controles ginecológicos (25-27); también ha sido muy importante la labor de los servicios de Medicina Interna - Unidades de Enfermedades Infecciosas, con un mayor control de la infección por VIH, intentando una mayor adherencia de los pacientes al tratamiento y, por tanto, una mejoría en su calidad de vida.

\section{GUTIÉRREZ DEL RÍO}

Servicio de Medicina Interna. Hospital de Cabueñes. Gijón. Asturias

\section{Bibliografía}

1. Muga R. Adicción a drogas y unidades de desintoxicación. Med Clin (Barc) 1991; 97: 337-339.

2. Gutiérrez del Río C, Casanueva Gutiérrez M, Nuño Mateo J, Fernández Bustamante J, Morís de la Tassa J. Unidad de desintoxicación hospitalaria: cuatro años de experiencia. Factores ambientales. An Med Interna (Madrid) 1998; 15 (11): 584-587.

3. Torres-Tortosa M, Ruiz López de Tejada M, Fernández Elías M, Pérez Pérez C, Fernández Conejero E, Ugarte I et al. Cambios en la vía de administración de la heroína y frecuencia de infección por el virus de la inmunodeficiencia humana. Med Clin (Barc) 1995; 104: 249-252.

4. Barrio G, de la Fuente L, Camí J. El consumo de drogas en España y su posición en el contexto europeo. Med Clin (Barc) 1993; 101: 344-355.

5. De la Fuente I, Barrio G, Vicente J, Bravo MJ, Lardelli P. Intravenous Administration Among Heroin Users Having Treatment in Spain. J Epidemiol 1994; 23: 805-811

6. De los Cobos Calleja T, Casanueva Gutiérrez M, Jové González C. Perfil de los usuarios de drogas ingresados en un hospital. An Med Interna (Madrid) 2003; 20: 504-509

7. Fernández J, López C, Arim MJ, Alameda J. Cambios en la vía de administración de drogas en heroinómanos. Rev Clin Esp 1993; 193: 76-77.

8. Gutiérrez del Río C, Casanueva Gutiérrez M, de la Fuente García B,
Gallo Alvaro C, Alcalde Fernández MLG, Morís de la Tassa J. Unidad de desintoxicación hospitalaria: cuatro años de experiencia. Tratamiento e infecciones. An Med Interna (Madrid) 1998; 15 (10): 528530.

9. Grupo de trabajo para estudio de infecciones en drogadictos. Estudio multicéntrico de las complicaciones infecciosas en adictos a drogas por vía parenteral en España: análisis de 11645 casos (1977-1988). Enf Infec y Microbiol Clin 1990; 8: 514-519.

10. Cherubin ChE, Joseph D, Sapira MD. The Medical Complications of Drug Addiction and the Medical Assessment of the Intravenous Drug Users: 25 Years Later. Ann Intern Med 1993; 119: 1017-1028.

11. Aviñó Rico MJ, Hernández Aguado I, Pérez Hoyos S, García de la Hera M, Ruiz I, Bohimar Monrull F. Incidencia de la infección por el virus de la inmunodeficiencia humana tipo I (VIH 1) en usuarios de droga por vía parenteral. Med Clin 1994; 102: 369-373

12. López de Munain J, Cámara MM, Santamaría JM, Zuriñe Zubero, Baraia-Etxaburu J, Muñoz J. Características clínico-epidemiológicas de los nuevos diagnósticos de infección por el virus de la inmunodeficiencia humana. Med Clin (Barc) 2001; 117: 654-656.

13. Torres-Tortosa M, Fernández-Elías M, Ugarte I, Ruiz López de Tejada M. Cambios en la vía de administración de drogas en heroinómanos. 
Rev Clin Esp 1993; 193: 76-77.

14. Krantz AJ, Hershow RC, Prachand N, Hayden DM, Franklin C, Hryhorczuk DO. Heroin insufflation as a Trigger for patients with life-threatening asthma. Chest 2003; 123: 510-517.

15. Mena M, Corvalan S, Bedregal P. Health care expenditures among the offspring of cocaine paste consumers. Rev Med Chil 2002; 130 (11): 1241-8.

16. Norris KC, Thornill-Joynes M, Tareen N. Cocaine use and chronic renal failure. Semin Nephrol 2001; 21: 362-366.

17. Weintraub E, Dixon L, Delahanty J, Schwuartz R, Johnson J, Cohen A, Klecz M. Reason for medical hospitalisation among adult alcohol and drug abusers. Am J Addict 2001; 10: 167-177.

18. Weber JE, Shofer FS, Larkin GL, Kalaria AS, Hollander JE. Validation of a brief observation period for patients with cocaine-associated chest pain. N Engl J Med 2003; 348: 487-488.

19. Wermth L. Methamphetamine use: Hazards and social influences. J Drug Educ 2000; 30: 423-433.

20. Paraherakis A, Charney DA, Gill K. Neuropsychological functioning in substance-dependent patients. Subst Use Misuse 2001; 36: 257-271.
21. Ochoa E. Drogas de diseño. Med Clin (Barc) 2002; 119: 375-376.

22. Abanades S, Farré M. Drogas de diseño. Med Clin (Barc) 2003; 121: 38.

23. Espinosa G, Miro O, Nogue S, To-Figuera J, Sánchez M, Coll-Vinnent B. Intoxicación por éxtasis líquido: estudio de 22 casos. Med Clin (Barc) 2001; 117: 56-58.

24. Abanades S, Iglesias ML, Echarte JL, Puig-Dou J, Roset PN, Farré M. Gammhydroxibutirate: a novel toxicological emergency. Methods Find Exp Clin Pharmacol 2001; 23: 326.

25. Pedrol E, Álvarez MT, Deig E, Andrés I, Ribell M, Soler A. Urgencias motivadas por pacientes controlados en un centro de atención y seguimiento de drogodependencias. Med Clin (Barc) 2003; 121: 18-20.

26. Suelves JM, Brugal MT, Cayla JA, Torralba L. Cambios en los problemas de salud provocados por la cocaína en Cataluña. Med Clin (Barc) 2001; 117: 581-583.

27. Cabot E, Soler A, Olid F, Tornero JC, Torrents A, Pedrol E, et al. Consumo de atención urgente derivada de la adicción a drogas. Emergencias 1997; 9 (Supl. 1): 238 